\title{
KINERJA PENDIDIKAN ANAK USIA DINI DAN PENDIDIKAN NONFORMAL BERDASARKAN MISI PENDIDIKAN
}

\section{PERFORMANCE OF EARLY CHILDHOOD EDUCATION AND NONFORMAL EDU- CATION BASED ON EDUCATION MISSION}

\author{
Ida Kintamani Dewi Hermawan \\ Pusat Data dan Statistik Pendidikan, Kemdikbud \\ Gedung E lantai Dasar, Jalan Jenderal Sudirman, Senayan-Jakarta \\ e-mail: idakintamani53@yahoo.com
}

Naskah diterima tanggal: 23/01/2015, Dikembalikan untuk direvisi tanggal: 22/03/2015, Disetujui tanggal: 01/04/2015

\begin{abstract}
The purpose of this writing is to study the potential of early childhood education (ECE) and nonformal education (NFE), educational indicators based on education mission, and performance of ECE and NFE. The method used is documentation or reference study. Analysis is held by descriptive method using educational indicators based on education mission, that is, availability, quality, equality, and assurance of service. The results shows that the potential of seven programs (literacy, ECE, Packet A, Packet B, Packet C and courses) had accommodated 12.9 million students, 575.6 thousand facilitators, and 160.9 thousands organizers. Besides that, based on education mission with the ideal value of 100 , the value of availability was 84.48 , quality was 59.92, equality was 83.85, and services assurance was 73.45 so that the performance became 75.43. To conclude, both ECE and NFE has the lowest performance from its quality and the highest performance from its availability.
\end{abstract}

Keywords: educational performance ECE NFE, educational mission, educational indicator

\begin{abstract}
Abstrak: Tujuan penulisan ini adalah untuk mengkaji potensi layanan pendidikan anak usia dini (PAUD) dan pendidikan nonformal (PNF), indikator pendidikan berdasarkan misi pendidikan, dan kinerja PAUD dan PNF tahun 2012. Metode yang digunakan adalah studi dokumentasi atau kepustakaan. Analisis dilakukan secara deskriptif menggunakan indikator pendidikan berdasarkan misi pendidikan, yaitu ketersediaan, kualitas, kesetaraan, kepastian layanan. Hasil kajian menunjukkan bahwa potensi 7 layanan pendidikan (pendidikan keaksaraan (PK), PAUD, TK, Paket A, Paket B, Paket C, dan kursus) telah berhasil menampung 12,9 juta peserta didik, dengan pendidik sebesar 575,6 ribu, dan pengelola sebesar 160,9 ribu. Selain itu, berdasarkan misi pendidikan dengan nilai ideal 100 maka ketersediaan sebesar 84,48, kualitas sebesar 59,92, kesetaraan sebesar 83,85, dan kepastian sebesar 73,45 sehingga kinerjanya menjadi 75,43. Simpulannya, kinerja PAUD dan PNF yang terendah adalah pada kualitas layanan dan yang tertinggi adalah pada ketersediaan layanan.
\end{abstract}

Kata kunci: kinerja pendidikan, PAUD, PNF, misi pendidikan, indikator pendidikan

\section{Pendahuluan}

Berdasarkan Undang-Undang Nomor 20, Tahun 2003 tentang Sistem Pendidikan Nasional (UU 20/2003) pasal 3, tujuan pendidikan adalah untuk berkembangnya potensi peserta didik agar menjadi marusia yang beriman dan bertakwa kepada Tuhan Yang Maha Esa, berakhlak mulia, sehat, berilmu, cakap, kreatif, mandiri, dan menjadi warga negara yang demokratis serta bertanggung jawab (Sekretariat Negara, 2003). Untuk mewujudkan tujuan tersebut terdapat tiga jalur pendidikan yang terdiri atas pendidikan formal, nonformal, dan informal. Pendidikan formal dilaksanakan secara terstruktur dan 
berjenjang yang diselenggarakan di sekolah dan perguruan tinggi. Pendidikan nonformal diselenggarakan bagi masyarakat untuk mendukung pendidikan sepanjang hayat. Pendidikan informal dilaksanakan oleh keluarga dan lingkungan yang bersifat mandiri.

Selanjutnya, Peraturan Menteri Pendidikan Nasional Nomor 49, Tahun 2007 tentang Standar Pengelolaan Pendidikan Nonformal (PNF) menyebutkan bahwa tujuan satuan pendidikan nonformal ada empat, yaitu 1) menggambarkan pencapaian tingkat mutu yang seharusnya dicapai dalam program pembelajaran; 2) mengacu pada visi, misi, dan tujuan pendidikan nasional serta relevan dengan kebutuhan pemberdayaan masyarakat; 3 ) diputuskan oleh pengelola dan/atau penyelenggara pendidikan nonformal dengan memperhatikan masukan dari berbagai pihak; 4) disosialisasikan kepada segenap pihak yang berkepentingan (Departemen Pendidikan Nasional, 2007).

Selain itu, berdasarkan pasal 28 ayat 1-5, pendidikan anak usia dini (PAUD) adalah suatu upaya pembinaan yang ditujukan kepada anak sejak lahir sampai dengan usia enam tahun yang dilakukan melalui pemberian rangsangan pendidikan untuk membantu pertumbuhan dan perkembangan jasmani dan rohani agar anak memiliki kesiapan dalam memasuki pendidikan lebih lanjut (Sekretariat Negara, 2003).

Sampai sekarang, studi tentang kinerja PAUD dan PNF belum pernah dilakukan. Demikian juga analisis terhadap data PAUD dan PNF belum pernah dilaksanakan padahal setiap tahun Pusat Data dan Statistik Pendidikan (PDSP) menghasilkan Statistik PAUD dan Statistik PNF. Pada tahun 2012 telah dihasilkan Statistik PAUD dan Statistik PNF. Untuk mengetahui apakah statistik yang dihasilkan merupakan cerminan hasil penyelenggaran PAUD dan PNF dan sudah memenuhi tujan PAUD dan PNF maka perlu dilakukan analisis terhadap penyelenggaraan PAUD dan PNF dilihat dalam bentuk kinerja menggunakan misi pendidikan $5 \mathrm{~K}$.

Berdasarkan layanan PAUD dan PNF maka timbul beberapa permasalahan, yaitu 1)
Bagaimana potensi layanan PAUD dan PNF?, 2) Bagaimana indikator pendidikan yang dihasilkan berdasarkan misi pendidikan dalam layanan PAUD dan PNF?, dan 3) Bagaimana kinerja PAUD dan PNF?

Sesuai dengan permasalahannya maka tujuan penulisan ini adalah: 1) mengkaji potensi layanan PAUD dan PNF tahun 2012, 2) mengkaji indikator pendidikan dari misi pendidikan seperti ketersediaan, kualitas, kesetaraan, dan kepastian memperoleh layanan PAUD dan PNF tahun 2012, dan 3) mengkaji kinerja layanan PAUD dan PNF tahun 2012.

\section{Kajian Pustaka Misi Pendidikan}

RPJMN Tahun 2010-2014 tersebut dijabarkan dalam Rencana Strategi Kemdiknas Tahun 2010-2014 (renstra). Renstra ini kemudian menjadi pedoman bagi semua tingkatan pengelola pendidikan dari pusat dan daerah dalam melaksanakan dan mengevaluasi program pembangunan pendidikan (Kementerian Pendidikan Nasional, 2010).

Sejalan dengan visi 2025 maka visi Kemdiknas 2014 adalah terselenggaranya layanan prima pendidikan nasional untuk membentuk insan cerdas komprehensif. Layanan prima pendidikan nasional tersebut adalah 1 ) tersedia secara merata di seluruh pelosok nusantara; 2) terjangkau oleh seluruh lapisan masyarakat; 3) berkualitas dan relevan dengan kebutuhan kehidupan bermasyarakat, dunia usaha, dan dunia industri; 4) setara bagi warga negara Indonesia dalam memperoleh pendidikan berkualitas dengan memperhatikan keberagaman latar belakang sosial-budaya, ekonomi, geografi, gender, dan sebagainya; dan 5) menjamin kepastian bagi warga negara Indonesia untuk dapat mengenyam pendidikan dan menyesuaikan diri dengan tuntutan masyarakat, dunia usaha, dan dunia industri (Kementerian Pendidikan Nasional, 2010).

Untuk mencapai visi Kemdiknas 2014, misi Kemdiknas 2010-2014 dikemas dalam "Misi Pendidikan 5K". Misi K1 adalah meningkatkan 
ketersediaan layanan, misi K2 adalah memperluas keterjangkauan layanan, misi K3 adalah meningkatkan kualitas dan relevansi layanan, misi K4 adalah mewujudkan kesetaraan dalam memperoleh layanan, dan misi $\mathrm{K} 5$ adalah menjamin kepastian memperoleh layanan (Kementerian Pendidikan Nasional, 2010).

Sesuai dengan judul artikel maka kinerja PAUD dan PNF akan dianalisis menggunakan misi pendidikan $5 \mathrm{~K}$ berdasarkan indikator pendidikan. Oleh karena ketersediaan data PAUD dan PNF terbatas maka tidak semua indikator pada misi pendidikan $5 \mathrm{~K}$ digunakan dalam analisis, misalnya misi kedua keterjangkauan layanan tidak digunakan.

\section{Pendidikan Nonformal (PNF)}

Berdasarkan Undang-Undang Nomor 20, Tahun 2003 tentang Sistem Pendidikan Nasional (UU 20/2003), pasal 26, PNF memiliki berfungsi mengembangkan potensi peserta didik dengan penekanan pada penguasaan pengetahuan dan keterampilan fungsional serta pengembangan sikap dan kepribadian profesional. PNF berfungsi sebagai pengganti, penambah, dan/atau pelengkap pendidikan formal dalam rangka mendukung pendidikan sepanjang hayat yang ditujukan bagi warga masyarakat yang memerlukan layanan pendidikan tidak rutin. PNF meliputi pendidikan kecakapan hidup, PAUD, pendidikan kepemudaan, pendidikan pemberdayaan perempuan, pendidikan keaksaraan, pendidikan keterampilan dan pelatihan kerja, pendidikan kesetaraan, serta pendidikan lain yang ditujukan untuk mengembangkan kemampuan peserta didik (Sekretariat Negara, 2003).

Berdasarkan UU 20/2003 pasal 26, satuan layanan PNF terdiri atas lembaga kursus, lembaga pelatihan, kelompok belajar, pusat kegiatan belajar masyarakat, dan majelis taklim, serta satuan pendidikan yang sejenis. Kursus dan pelatihan diselenggarakan bagi masyarakat yang memerlukan bekal pengetahuan, keterampilan, kecakapan hidup, dan sikap untuk mengembangkan diri, mengembangkan profesi, bekerja, usaha mandiri, dan/atau melanjutkan pendidikan ke jenjang yang lebih tinggi. Hasil PNF dapat dihargai setara dengan hasil program pendidikan formal setelah melalui proses penilaian penyetaraan oleh lembaga yang ditunjuk oleh Pemerintah atau pemerintah daerah dengan mengacu pada standar nasional pendidikan (Sekretariat Negara, 2003).

PNF merupakan salah satu jalur pendidikan yang menggarap layanan pendidikan di luar sistem persekolahan yang bersifat formal. PNF tidak hanya berorientasi pada pengembangan pengetahuan dan keterampilan melainkan juga ditekankan pada adanya proses pemberdayaan masyarakat secara berkelanjutan. Oleh karena itu, proses pembelajaran di PNF tidak sekedar proses mekanis melainkan sebuah transformasi nilai melalui proses yang berkelanjutan sepanjang hayat. Dengan cara demikian, perubahan yang diinginkan melalui PNF dapat lebih dihayati oleh masyarakat (Sudjana, 2001).

Jenis PNF yang dilakukan analisis adalah pendidikan keaksaraan, Paket $A$, Paket $B$, Paket $C$, dan kursus karena hanya lima program tersebut yang memiliki data yang cukup lengkap untuk dilakukan analisis. Layanan lima program tersebut dikaitkan dengan misi pendidikan, yaitu ketersediaan, kualitas, kesetaraan, dan kepastian memperoleh layanan PNF.

\section{Pendidikan Anak Usia Dini (PAUD)}

Berdasarkan UU 20/2003 pasal 28, PAUD diselenggarakan sebelum jenjang pendidikan dasar. PAUD dapat diselenggarakan melalui jalur pendidikan formal, nonformal, dan/atau informal. PAUD pada jalur pendidikan formal berbentuk taman kanak-kanak (TK), raudlatul athfal (RA), atau bentuk lain yang sederajat. PAUD pada jalur pendidikan nonformal berbentuk kelompok bermain (KB), taman penitipan anak (TPA), atau bentuk lain yang sederajat. PAUD pada jalur pendidikan informal berbentuk pendidikan keluarga atau pendidikan yang diselenggarakan oleh lingkungan (Sekretariat Negara, 2003).

Berdasarkan Peraturan Pemerintah RI Nomor 17, Tahun 2010 tentang Pengelolaan dan 
Penyelenggaraan Pendidikan, fungsi dan tujuan PAUD diatur dalam Pasal 61. PAUD mempunyai fungsi untuk membina, menumbuhkan, dan mengembangkan seluruh potensi anak usia dini secara optimal, sehingga terbentuk perilaku dan kemampuan dasar sesuai dengan tahap perkembangannya agar memiliki kesiapan untuk memasuki sekolah dasar. Tujuan PAUD ada dua, yaitu membangun landasan bagi berkembangnya potensi peserta didik agar menjadi manusia beriman dan bertakwa kepada Tuhan Yang Maha Esa, berakhlak mulia, berkepribadian luhur, sehat, berilmu, cakap, kritis, kreatif, inovatif, mandiri, percaya diri, dan menjadi warga negara yang demokratis dan bertanggung jawab serta mengembangkan potensi kecerdasan spiritual, intelektual, emosional, kinestetis, dan sosial peserta didik pada masa emas pertumbuhannya dalam lingkungan bermain yang edukatif dan menyenangkan. (Sekretariat Negara, 2010).

Jenis PAUD yang dilakukan analisis adalah TK dan PAUD Nonformal karena hanya dua program tersebut yang memiliki data cukup lengkap untuk dilakukan analisis. Layanan TK dan PAUD Nonformal dikaitkan dengan misi pendidikan, yaitu ketersediaan, kualitas, kesetaraan, dan kepastian memperoleh layanan PAUD.

\section{Indikator Pendidikan}

Indikator merupakan penjabaran dari kompetensi dasar yang menunjukkan tanda-tanda perbuatan dan respon yang dilakukan atau ditampilkan oleh peserta didik. Indikator juga dikembangkan sesuai dengan karakteristik satuan pendidikan, potensi daerah, dan peserta didik dan juga dirumuskan dalam rapat kerja operasional yang dapat diukur dan diobservasi sehingga dapat digunakan sebagai dasar dalam penyusunan alat penilaian. Jadi "indikator merupakan kompetensi dasar secara spesifik yang dapat dijadikan untuk menilai ketercapaian hasil pembelajaran dan juga dijadikan tolok ukur sejauh mana penguasaan siswa terhadap suatu pokok bahasan atau mata pelajaran tertentu" (Sultan, 2015). Pengertian lain indikator seperti yang dikutip dari dilihatya.com (2014) adalah "Indikator merupakan ukuran, karakteristik, ciri-ciri perbuatan dan proses yang berkontribusi atau menunjukkan ketercapaian suatu kompetensi dasar. Indikator dirumuskan dengan menggunakan kata kerja operasional yang dapat diukur seperti mengidentifikasi, menghitung, membedakan, menyimpulkan, mendemonstrasi-kan, dan mendeskripsikan. Indikator pencapaian hasil belajar dari setiap kompetensi hasil belajar merupakan acuan untuk melakukan penilaian".

Indikator merupakan petunjuk adanya suatu konsep dan sekaligus ukuran. Sebagai suatu konsep, indikator pendidikan merupakan besaran kuantitatif yang dapat digunakan untuk mengukur proses dan hasil pendidikan atau dampak dari suatu instrumen kebijakan di bidang pendidikan. Sebagai ukuran, indikator pendidikan merupakan besaran dari suatu gejala tertentu sebagai hasil pengolahan dari dua satuan data atau lebih dalam waktu yang bersamaan. Namun, secara sederhana, indikator juga didefinisikan sebagai perbandingan antara dua atau lebih variabel pendidikan, sehingga dapat diinterpretasikan (Kintamani, 2013).

Dengan demikian, indikator pendidikan yang digunakan dalam menghitung kinerja PAUD dan PNF adalah menggunakan dua jenis variabel pendidikan sehingga mudah dilakukan interpretasi. Indikator tersebut juga dikaitkan dengan misi pendidikan seperti ketersediaan, kualitas, kesetaraan, dan kepastian layanan PAUD dan PNF.

\section{Kinerja}

Kinerja adalah kata dalam bahasa Indonesia berasal dari kata dasar "kerja" yang menerjemahkan dari bahasa asing prestasi atau hasil kerja. Menurut Mangkunegara (2000), kinerja (prestasi kerja) adalah hasil kerja secara kualitas dan kuantitas yang dicapai oleh seseorang pegawai dalam melaksanakan tugasnya sesuai dengan tanggung jawab yang diberikan kepadanya. Menurut Sulistyarini (2003), kinerja 
seseorang merupakan kombinasi dari kemampuan, usaha dan kesempatan yang dapat dinilai dari hasil kerjanya.

Kinerja berkaitan dengan layanan publik seperti yang dikutip dari Kinerja.or.id "kinerja merupakan program yang bertujuan meningkatkan tata kelola dalam penyediaan layanan publik di Indonesia. Dalam rangka mencapai perubahan dalam penyediaan layanan publik yang berkelanjutan, kerja sama dengan pemerintah daerah dibutuhkan untuk membuat penyediaan layanan publik lebih responsif. Seraya, tetap meningkatkan kapasitas masyarakat sipil dan masyarakat untuk menuntut kualitas pelayanan yang lebih baik dari pemerintah".

Dengan demikian, kinerja PAUD dan PNF adalah program pendidikan yang bertujuan untuk meningkatkan layanan PAUD dan PNF dengan menggunakan indikator-indikator misi pendidikan yang disajikan dalam bentuk nilai, nilai 100 adalah yang tertinggi dan nilai 0 adalah yang terendah.

\section{Metode}

Metode yang digunakan dalam menghitung kinerja PAUD dan Nonformal berdasarkan misi pendidikan menggunakan pendekatan studi dokumentasi, sehingga merupakan data sekunder. Menurut Arikunto (2010) bahwa dokumentasi dari kata "dokumen" yang artinya barang-barang tertulis. Untuk melaksanakan studi dokumentasi digunakan benda-benda tertulis atau bahan yang terkait dengan PAUD dan PNF yang tersedia di PDSP dan lingkungan Kemdikbud baik berupa data dan informasi yang tersedia di Statistik PAUD dan Statistik Pendidikan Nonformal (PNF), aspek hukum tentang PAUD dan PNF yang ada dalam undangundang, peraturan pemerintah, peraturan Menteri Pendidikan dan Kebudayaan, pedoman maupun berbagai tulisan ilmiah atau penelitian lainnya. Dengan demikian, sumber data utama yang digunakan adalah Statistik PAUD dan Statistik PNF, Tahun 2012 yang dipublikasikan oleh PDSP. Satuan analisis pada tingkat nasional.
Menurut Soeharsono (1995), studi dokumentasi adalah penelitiarn yang tidak langsung ditujukan pada subjek penelitian. Dokumen yang digunakan adalah sekunder, yaitu Statistik PAUD dan Statistik PNF. Keuntungan menggunakan studi dokumentasi karena subjek penelitian sulit dijangkau, data tidak terpengaruh, analisis bisa menjangkau masa lalu, dan besarnya sampel. Kerugiannya karena ada data yang tidak dapat disediakan, hanya variabel tertentu, tidak lengkap, dan format tidak baku.

Pengumpulan data dilaksanakan menggunakan beberapa item data untuk menjaring data sekunder yang meliputi data PAUD dan PNF. Untuk menghasilkan data yang valid dan reliabel maka dilakukan wawancara dan diskusi kepada para pemegang data di PDSP dan di lingkungan Kemdikbud sebagai responden. Selanjutnya, dilakukan analisis data yang digunakan untuk menjawab tujuan penelitian tentang kinerja PAUD dan PNF. Teknik analisis yang digunakan adalah analisis deskriptif dengan memberikan interpretasi terhadap hasil analisis PAUD dan PNF.

\section{Standar Konversi}

Untuk menentukan kinerja PAUD dan PNF menggunakan 18 indikator dari 4 misi pendidikan maka dilakukan konversi nilai karena tidak semua indikator memiliki nilai ideal 100. Standar konversi kinerja PAUD dan PNF disajikan pada Tabel 3.

Indikator ketersediaan, yaitu R-PD/KB/Lbg dan $\mathrm{R}-\mathrm{P} / \mathrm{KB} / \mathrm{Lbg}$ untuk program PAUD dan PNF tidaklah sama dan belum ada ketentuan ideal. Oleh karena itu, untuk setiap program ditentukan berbeda. Begitu juga \%LbgPem khusus kursus. Untuk indikator kualitas maka digunakan tiga jenis, yaitu dari peserta didik, pendidik, dan pengelola. Untuk \%PD usia ditentukan ideal 100 kecuali PAUD ditentukan 50 karena sebagian berada di TK. Untuk \%PU khusus program pendidikan kesetaraan ditentukan ideal 100. Untuk \%Lls khusus program pendidikan kesetaraan dan kursus ditentukan ideal 100. Rasio PD/P ditentukan 
Tabel 1 Variabel Data untuk Menghitung Indikator Layanan PAUD dan PNF

\begin{tabular}{|c|c|c|c|c|c|c|c|c|}
\hline No. & Jenis Data & $\mathrm{PK}$ & PAUD & TK & Paket A & Paket B & Paket C & Kursus \\
\hline \multirow[t]{3}{*}{1} & Peserta Didik (PD) & $v$ & $v$ & $v$ & $v$ & $v$ & $v$ & $v$ \\
\hline & a. Menurut Usia & v & $v$ & - & $v$ & $v$ & $v$ & - \\
\hline & b. Status Sekolah & - & - & $\mathrm{v}$ & - & - & - & - \\
\hline 2 & Pengikut Ujian (PU) & - & - & - & $v$ & $v$ & v & - \\
\hline 3 & Lulusan (LIs) & - & - & - & $\mathrm{v}$ & v & v & $\mathrm{v}$ \\
\hline \multirow[t]{3}{*}{4} & Kelompok Belajar (KB) & $v$ & - & - & $v$ & $v$ & $v$ & - \\
\hline & Lembaga (Lbg) & - & v & $v$ & - & - & - & v \\
\hline & a. Menurut Sumber Pendanaan & - & - & - & - & - & - & $v$ \\
\hline \multirow[t]{6}{*}{6} & Pendidik (P) & v & $v$ & $v$ & $v$ & $v$ & v & v \\
\hline & a. Menurut Ijazah & $v$ & $v$ & $v$ & $v$ & $v$ & v & v \\
\hline & b. Menurut Pekerjaan & $v$ & $v$ & - & $v$ & $v$ & v & - \\
\hline & c. Menurut Jenis Kelamin & $v$ & $v$ & $v$ & $v$ & $v$ & v & v \\
\hline & d. Menurut Pelatihan & v & v & - & - & - & - & - \\
\hline & e. Menurut Kepegawaian & - & - & $\mathrm{v}$ & - & - & - & - \\
\hline \multirow[t]{3}{*}{7} & Pengelola (PA) & v & $v$ & $v$ & $v$ & $v$ & v & - \\
\hline & a. Menurut Ijazah & $v$ & $v$ & $v$ & $v$ & $v$ & $v$ & - \\
\hline & b. Menurut Jenis Kelamin & - & $v$ & $v$ & $v$ & $v$ & v & - \\
\hline \multirow[t]{2}{*}{8} & Penduduk Usia Sekolah (PUS) & - & $v$ & $v$ & $v$ & $v$ & $v$ & - \\
\hline & Penduduk Usia Masuk Sekolah (PUM) & - & - & v & - & - & - & - \\
\hline
\end{tabular}

Catatan: PK adalah pendidikan keaksaraan

untuk setiap program berbeda karena belum ada ketentuan ideal. Untuk \%PS1+ ditentukan ideal 100 kecuali pendidikan keaksaraan dan PAUD ditentukan 50. Untuk \%Pguru ditentukan ideal 100 di setiap program. Untuk \%PPn ditentukan ideal 50, artinya tidak ada perbedaan antara pendidik laki-laki dan perempuan dalam mengajar PAUD dan PNF. Untuk \%PLn ditentukan ideal 100, artinya semua pendidik telah memperoleh pelatihan tentang PAUD dan PNF. Untuk \%PT khusus TK ditentukan ideal 100, artinya semua pendidik mempunyai status kepegawaian tetap. Untuk \%PAS1+ ditentukan ideal 100 di semua program. Untuk \%PAPn ditentukan ideal $100 \mathrm{di}$ setiap program. Untuk indikator kesetaraan, PG PD/PG APK ditentukan ideal $0 \%$ artinya tidak ada perbedaan antara laki-laki dan perempuan. RG PD/IPG APK ditentukan ideal 1, artinya ada kesetaraan antara laki-laki dan perempuan. Untuk \%PD-Swt khusus TK ditentukan 95\% karena sebagian besar TK adalah swasta.
Indikator kepastian, APK ditentukan berbeda untuk setiap program, sedangkan AMK khusus TK ditentukan 30\% karena sepertiga peserta didik TK sebagai peserta didik baru.

Dengan menggunakan standar konversi untuk semua indikator pendidikan tersebut maka dapat dihitung nilai setiap misi dan gabungan dari keempat misi tersebut menjadi satu nilai menghasilkan kinerja layanan PAUD dan PNF. Dengan demikian, berdasarkan standar tersebut maka nilai yang terbesar adalah 100 dan terkecil adalah 1 (Kintamani, 2012).

\section{Hasil Kajian dan Pembahasan Potensi Layanan PAUD dan PNF}

Berdasarkan data PAUD dan PNF yang diperoleh dari Statistik PAUD dan Statistik PNF tahun 2012 yang disajikan pada Tabel 4 maka dapat diketahui potensi layanan PAUD dan PNF. (PDSP, 2013a dan PDSP, 2013b). 
Tabel 2 Indikator Layanan PAUD dan PNF

\begin{tabular}{|c|c|c|c|c|c|c|c|c|c|}
\hline No. & Jenis Indikator & Penjelasan & $\mathrm{PK}$ & PAUD & TK & Paket A & Paket B & Paket C & Kursus \\
\hline \multicolumn{10}{|c|}{ Ketersediaan Layanan: Misi K1 } \\
\hline 1 & R-PD/KB/Lbg & $\begin{array}{l}\text { Didik/Kelompok } \\
\text { Belajar/Lembaga }\end{array}$ & $\mathrm{V}$ & $\mathrm{V}$ & V & V & $\mathrm{V}$ & $\mathrm{V}$ & $\mathrm{V}$ \\
\hline 2 & $\mathrm{R}-\mathrm{P} / \mathrm{KB} / \mathrm{Lbg}$ & Rasio Pendidik/Kelompok Bela. & $\mathrm{v}$ & $\mathrm{v}$ & $\mathrm{v}$ & v & $\mathrm{v}$ & $\mathrm{v}$ & v \\
\hline 3 & \%Lbg Pem & \%Lembaga Pemerintah & - & - & - & - & - & - & $\mathrm{v}$ \\
\hline
\end{tabular}

Kualitas Layanan: Misi K3

\begin{tabular}{|c|c|c|c|c|c|c|c|c|c|}
\hline 4 & \%PD Usia & \%Peserta Didik usia sekolah & v & $\mathrm{v}$ & - & $\mathrm{v}$ & $\mathrm{v}$ & $\mathrm{v}$ & - \\
\hline 5 & $\% \mathrm{PU}$ & \%Peserta Ujian & - & - & - & $\mathrm{v}$ & $\mathrm{v}$ & $\mathrm{v}$ & - \\
\hline 6 & $\%$ LIs & $\%$ Lulusan & - & - & - & $\mathrm{V}$ & $\mathrm{v}$ & $\mathrm{v}$ & $\mathrm{v}$ \\
\hline 7 & $\mathrm{R}-\mathrm{PD} / \mathrm{P}$ & Rasio Peserta Didik/Pendidik & v & $\mathrm{v}$ & $\mathrm{v}$ & $\mathrm{v}$ & $\mathrm{v}$ & $\mathrm{v}$ & $\mathrm{v}$ \\
\hline 8 & $\% P S 1+$ & \%Pendidik S1 lebih tinggi & v & $v$ & $v$ & $\mathrm{v}$ & $\mathrm{v}$ & $v$ & $\mathrm{v}$ \\
\hline 9 & $\%$ PGuru & \%Pendidik Guru & V & $\mathrm{v}$ & - & $\mathrm{v}$ & $\mathrm{v}$ & $\mathrm{v}$ & - \\
\hline 10 & $\% P P n$ & \%Pendidik Perempuan & $\mathrm{v}$ & $\mathrm{v}$ & $\mathrm{v}$ & $\mathrm{v}$ & $\mathrm{v}$ & $\mathrm{v}$ & $\mathrm{v}$ \\
\hline 11 & $\% P L n$ & \%Pendidik Pelatihan & $\mathrm{v}$ & $\mathrm{v}$ & - & - & - & - & - \\
\hline 12 & $\% \mathrm{PT}$ & \%Pendidik Tetap & - & - & $\mathrm{v}$ & - & - & - & - \\
\hline 13 & $\%$ PAS1 + & \%Pengelola S1 lebih tinggi & $\mathrm{v}$ & $\mathrm{v}$ & $\mathrm{v}$ & $\mathrm{v}$ & $\mathrm{v}$ & $\mathrm{v}$ & - \\
\hline 14 & $\%$ PAPn & \%Pengelola Perempuan & - & $\mathrm{v}$ & $\mathrm{v}$ & $\mathrm{v}$ & $\mathrm{v}$ & $\mathrm{v}$ & - \\
\hline \multicolumn{10}{|c|}{ Kesetaraan Layanan: Misi K4 } \\
\hline 15 & PG & Perbedaan Gender & $\mathrm{v}$ & $\mathrm{v}$ & v & v & $\mathrm{v}$ & $\mathrm{v}$ & $\mathrm{v}$ \\
\hline 16 & RG/IPG & $\begin{array}{l}\text { Rasio Gender/Indeks Paritas } \\
\text { Gender }\end{array}$ & $\mathrm{V}$ & $\mathrm{V}$ & V & $\mathrm{V}$ & $\mathrm{V}$ & V & $\mathrm{v}$ \\
\hline 17 & $\%$ PD-Swt & \%Peserta Didik Swasta & - & - & $\mathrm{v}$ & - & - & - & - \\
\hline \multicolumn{10}{|c|}{ Kepastian Layanan: Misi K5 } \\
\hline 18 & APK & Angka Partisipasi Kasar & - & $\mathrm{v}$ & v & $\mathrm{v}$ & v & $\mathrm{v}$ & - \\
\hline 19 & AMK & Angka Masukan Kasar & - & - & $\mathrm{v}$ & - & - & - & - \\
\hline
\end{tabular}

Berdasarkan Tabel 4, layanan PAUD dan PNF telah mampu menampung 12,9 juta peserta didik. Layanan terbesar pada PAUD sebesar 6,6 juta dan terkecil pada program Paket $A$ sebesar 69,9 ribu. Kelompok belajar sebesar 33,0 ribu untuk pendidikan keaksaraan, Paket $A$, Paket B, dan Paket C. Lembaga sebesar 181,2 ribu untuk PAUD, TK, dan Kursus. Pendidik sebesar 575,6 ribu orang, terbesar juga pada PAUD sebesar 232,7 ribu dan terkecil juga pada Paket A sebesar 3,9 ribu. Pengelola sebesar 160,9 ribu orang (belum termasuk pengelola kursus), terbesar pada TK sebesar 71,4 ribu dan terkecil pada Paket $A$ sebesar 4,9 ribu. Penduduk usia 0-6 tahun sebesar 33,1 juta, penduduk 4-6 tahun sebesar 13,9 juta, penduduk 7-12 tahun sebesar 26,9 juta, penduduk 13-15 tahun sebesar 13,3 juta, dan penduduk 16-18 tahun sebesar 13,0 juta. Dengan demikian, dapat dikatakan PAUD dan PNF mampu mendukung penyelenggaraan pendidikan formal khususnya dalam pemerataan dan akses pendidikan.

\section{Indikator PAUD dan PNF Berdasarkan Misi Pendidikan}

Berdasarkan Tabel 5 dapat diketahui ketersediaan layanan PAUD dan PNF pada 7 bentuk layanan pendidikan. R-PD/KB/Lbg sebesar 60 , terbesar pada kursus sebesar 91 dan terkecil pada PK sebesar 10. Hal ini berarti kepadatan 
Tabel 3 Standar Konversi Kualitas Layanan PAUD dan PNF

\begin{tabular}{|c|c|c|c|c|c|c|c|c|}
\hline No. & Indikator & PK & PAUD & TK & Paket A & Paket B & Paket C & Kursus \\
\hline \multicolumn{9}{|c|}{ Ketersediaan Layanan: Misi K1 } \\
\hline 1 & R-PD/KB/Lbg & 10.00 & 80.00 & 60.00 & 30.00 & 40.00 & 40.00 & 100.00 \\
\hline 2 & $\mathrm{R}-\mathrm{P} / \mathrm{KB} / \mathrm{Lbg}$ & 1.00 & 3.00 & 4.00 & 2.00 & 5.00 & 6.00 & 2.00 \\
\hline 3 & \%Lbg Pem & - & - & - & - & - & - & 15.00 \\
\hline \multicolumn{9}{|c|}{ Kualitas Layanan: Misi K3 } \\
\hline 1 & \%PD Usia & 100.00 & 50.00 & - & 100.00 & 100.00 & 100.00 & - \\
\hline 2 & $\% P U$ & - & - & - & 100.00 & 100.00 & 100.00 & - \\
\hline 3 & \%Lls & - & - & - & 100.00 & 100.00 & 100.00 & 100.00 \\
\hline 4 & Rasio PD/P & 10.00 & 30.00 & 20.00 & 20.00 & 15.00 & 12.00 & 40.00 \\
\hline 5 & $\% P S 1+$ & 50.00 & 50.00 & 100.00 & 100.00 & 100.00 & 100.00 & 100.00 \\
\hline 6 & \%PGuru & 100.00 & 100.00 & - & 100.00 & 100.00 & 100.00 & - \\
\hline 7 & $\%$ PPn & 50.00 & 50.00 & 50.00 & 50.00 & 50.00 & 50.00 & 50.00 \\
\hline 8 & $\%$ PLn & 100.00 & 100.00 & - & - & - & - & - \\
\hline 9 & $\% \mathrm{PT}$ & - & - & 100.00 & - & - & - & - \\
\hline 10 & $\%$ PAS1+ & 50.00 & 50.00 & 100.00 & 100.00 & 100.00 & 100.00 & - \\
\hline 11 & $\%$ PAPn & - & 50.00 & 50.00 & 50.00 & 50.00 & 50.00 & - \\
\hline \multicolumn{9}{|c|}{ Kesetaraan Layanan: Misi K4 } \\
\hline 1 & PG PD/PG APK & 0.00 & 0.00 & 0.00 & 0.00 & 0.00 & 0.00 & 0.00 \\
\hline 2 & RG PD/IPG APK & 1.00 & 1.00 & 1.00 & 1.00 & 1.00 & 1.00 & 1.00 \\
\hline 3 & $\%$ PD-Swt & - & - & 95.00 & - & - & - & - \\
\hline \multicolumn{9}{|c|}{ Kepastian Layanan: Misi K5 } \\
\hline 1 & APK & - & 30.00 & 30.00 & 0.30 & 2.00 & 2.20 & - \\
\hline 2 & AMK & - & - & 30.00 & - & - & - & \\
\hline
\end{tabular}

yang rendah pada PK karena disesuaikan dengan kebijakan setiap kelompok belajar terdapat 10 peserta didik. Dilhat dari R-P/KB/Lbg sebesar 3 dan terbesar pada program Paket $C$ sebesar 6 dan terkecil juga pada PK sebesar 1. Hal ini berarti pendidik banyak terdapat pada program Paket C karena adanya 20 mata pelajaran.

Berdasarkan Tabel 6 dapat diketahui kualitas layanan PAUD dan PNF pada 7 bentuk layanan pendidikan. R-PD/P sebesar 22, terbesar pada kursus sebesar 39 dan terkecil pada program Paket $\mathrm{C}$ sebesar 6 . Artinya, pendidik melayani siswa terbesar pada kursus karena peserta didik pada kursus bervariasi ada yang hanya tiga bulan, enam bulan atau setahun. Sebaliknya, pendidik program Paket $C$ hanya melayani 6 orang peserta didik karena memang pendidiknya merupakan pengampu mata pelajaran.

Pendidik yang memiliki ijazah S1 dan yang lebih tinggi dari 7 bentuk layanan pendidikan sebesar 29,13\% dengan rincian paling sedikit pada PAUD sebesar $14,49 \%$ dan paling banyak pada program Paket $C$ sebesar $77,01 \%$. Besarnya pendidik program Paket $C$ karena sebagian besar dari guru, sebaliknya kecilnya pendidik PAUD karena hanya separuh yang berasal dari guru dan walau sudah ketentuan pendidik PAUD minimal berijazah S1. Pendidik perempuan dari 7 bentuk layanan pendidikan ternyata menempati posisi dominan, yaitu sebesar $85,93 \%$, terbanyak pada TK sebesar $97,42 \%$ dan palin sedikit pada program Paket B sebesar $43,08 \%$. Besarnya pendidik perempuan 
Tabel 4 Potensi Layanan PAUD dan PNF Tahun 2012

\begin{tabular}{|c|c|c|c|c|c|c|c|c|c|}
\hline No. & Jenis Data & PK & PAUD & TK & Paket A & Paket B & Paket C & Kursus & Jumlah \\
\hline \multirow[t]{3}{*}{1} & Peserta Didik (PD) & 197,298 & $6,601,180$ & $3,993,929$ & 69,905 & 142,004 & 256,262 & $1,679,587$ & $12,940,165$ \\
\hline & a. Menurut Usia & 88,386 & $3,293,422$ & $1,868,084$ & 7,624 & 25,317 & 77,684 & - & - \\
\hline & b. Swasta & - & - & $3,829,360$ & - & - & - & - & - \\
\hline 2 & Pengikut Ujian (PU) & - & - & - & 38,413 & 82,046 & 179,043 & - & - \\
\hline 3 & Lulusan (Lls) & - & - & - & 26,606 & 59,768 & 140,517 & $1,074,969$ & - \\
\hline 4 & Kelompok Belajar (KB) & 19,460 & - & - & 2,590 & 4,050 & 6,923 & - & 33,023 \\
\hline \multirow[t]{2}{*}{5} & Lembaga (Lbg) & - & 91,397 & 71,356 & - & - & - & 18,489 & 181,242 \\
\hline & a. Dana dari pemerintah & - & - & - & - & - & - & 2,104 & \\
\hline \multirow[t]{6}{*}{6} & Pendidik (P) & 21,275 & 232,679 & 213,823 & 3,962 & 19,885 & 41,334 & 42,594 & 575,552 \\
\hline & a. Ijazah S1 \& lebih tinggi & 4,832 & 33,708 & 61,012 & 1,692 & 12,420 & 31,830 & 22,163 & 167,657 \\
\hline & b. Berasal dari Guru & 10,574 & 116,068 & - & 2,330 & 13,550 & 29,162 & - & - \\
\hline & c. Perempuan & 12,722 & 221,828 & 208,296 & 2,150 & 8,566 & 18,416 & 22,573 & 494,551 \\
\hline & d. Mengikuti Pelatihan & 12,325 & 119,789 & - & - & - & - & - & - \\
\hline & e. Tetap & - & - & 121,194 & - & - & - & - & - \\
\hline \multirow[t]{3}{*}{7} & Pengelola (PA) & 17,473 & 45,096 & 71,356 & 4,974 & 7,940 & 14,074 & - & 160,913 \\
\hline & a. Ijazah S1 \& lebih tinggi & 6,582 & 15,234 & 20,696 & 2,453 & 4,516 & 8,774 & - & - \\
\hline & b. Perempuan & - & 39,681 & 68,010 & 2,165 & 3,048 & 5,243 & - & - \\
\hline \multirow[t]{2}{*}{8} & Penduduk Usia Sekolah (PUS) & - & $33,097,800$ & $13,903,400$ & $26,927,400$ & $13,308,900$ & $13,075,500$ & - & - \\
\hline & Penduduk Usia Masuk Sek (PUM) & - & - & $9,301,700$ & - & - & - & - & - \\
\hline
\end{tabular}

Catatan: PK adalah pendidikan keaksaraan, peserta didik PK usia $>44$ th, PAUD 0-3 th, TK usia $<6$ th, Paket A usia 7-12 th, Paket B usia 13-15 th, dan Paket C usia 16-18 th

Sumber: Statistik PAUD dan Pendidikan Nonformal, Tahun 2012 (PDSP, 2013a dan PDSP, 2013b)

Tabel 5 Indikator Ketersediaan Layanan PAUD dan PNF Tahun 2012

\begin{tabular}{llrrrrrrrr}
\hline No. & \multicolumn{1}{c}{ Indikator } & PK & PAUD & TK & Paket A & Paket B & Paket C & Kursus & Rata2 \\
\hline 1 & Rasio PD/KB/Lbg & 10.14 & 72.23 & 55.97 & 26.99 & 35.06 & 37.02 & 90.84 & 60.39 \\
2 & Rasio P/KB/Lbg & 1.09 & 2.55 & 3.00 & 1.53 & 4.91 & 5.97 & 2.30 & 2.69 \\
3 & \%Lbg Pem & - & - & - & - & - & - & 11.38 & - \\
\hline
\end{tabular}

Tabel 6 Indikator Kualitas Layanan PAUD dan PNF Tahun 2012

\begin{tabular}{llrrrrrrrr}
\hline No. & Jenis Program & PK & PAUD & TK & Paket A & Paket B & Paket C & Kursus & Rata2 \\
\hline 1 & \%PD Usia & 44.80 & 49.89 & - & 10.91 & 17.83 & 30.31 & - & - \\
2 & \%PU & - & - & - & 54.95 & 57.78 & 69.87 & - & - \\
3 & \%Lls & - & - & - & 69.26 & 72.85 & 78.48 & 64.00 & - \\
4 & Rasio PD/P & 9.27 & 28.37 & 18.68 & 17.64 & 7.14 & 6.20 & 39.43 & 22.48 \\
5 & \%PS1+ & 22.71 & 14.49 & 28.53 & 42.71 & 62.46 & 77.01 & 52.03 & 29.13 \\
6 & \%PGuru & 49.70 & 49.88 & - & 58.81 & 68.14 & 70.55 & - & - \\
7 & \%PPn & 59.80 & 95.34 & 97.42 & 54.27 & 43.08 & 44.55 & 53.00 & 85.93 \\
8 & \%PLn & 57.93 & 51.48 & - & - & - & - & - & - \\
9 & \%PT & - & - & 56.68 & - & - & - & - & \\
10 & \%PAS1+ & 37.67 & 33.78 & 29.00 & 49.32 & 56.88 & 62.34 & - & - \\
11 & \%PAPn & - & 87.99 & 95.31 & 43.53 & 38.39 & 37.25 & - & - \\
\hline
\end{tabular}


akibat perempuan lebih luwes dalam mengajar peserta didik TK dan PAUD dan sesuai dengan pendapat para psikolog bahwa anak usia balita lebih baik diasuh atau dididik oleh perempuan. Selain itu, masih ada anggapan bahwa guru PAUD haruslah perempuan dengan pemikiran berdasarkan sifat perempuan yang lebih keibuan jika dibandingkan dengan laki-laki (edukasi. kompasiana.com/2014/12/17).

Berdasarkan Tabel 7, PG PD pada PK terjadi perbedaan sangat besar, yaitu 38,19\% yang berarti peserta didik perempuan sangat lebih banyak daripada laki-laki. Sebaliknya, PG PD Paket A sangat kecil perbedaannya sebesar $0,03 \%$ yang berarti laki-laki sedikit lebih besar daripada perempuan. Akibatnya, RG PK juga sangat besar sebesar 2,24, artinya tidak ada kesetaraan antara peserta didik laki-laki dan perempuan. Sebaliknya, yang terkecil pada TK sebesar 1,03 , artinya mendekati setara walaupun perempuan sedikit lebih besar daripada laki-laki yang bersekolah di TK.

Berdasarkan Tabel 8, APK terbesar terjadi pada TK sebesar $28,73 \%$, dari penduduk usia 4-6 tahun dan terkecil terjadi pada program
Paket $A$ sebesar $0,26 \%$. Ini menunjukkan partisipasi peserta didik program Paket A dalam penyelenggaraan pendidikan sangat kecil jika dibandingkan dengan jenjang lainnya.

\section{Nilai PAUD dan PNF Berdasarkan Misi Pendidikan}

Berdasarkan Tabel 9, ketersediaan 7 bentuk layanan pendidikan berdasarkan 3 jenis indikator sebesar 84,48. Artinya ketersediaan layanan PAUD dan PNF tercapai sekitar $85 \%$. PK mendukung ketersediaan yang terbesar 98,64 dan terkecil pada kursus sebesar 61,59.

Berdasarkan Tabel 10, kualitas 7 bentuk layanan pendidikan berdasarkan 11 jenis indikator sebesar 59,92, artinya kualitas layanan PAUD dan Nonformal tercapai sekitar tiga perlimanya. Program Paket $\mathrm{C}$ mendukung kualitas terbesar, yaitu 68,98 dan terkecil pada TK sebesar 45,91. Kecilnya kualitas TK karena pendidik dan pengelola yang berijazah S1 dan lebih tinggi sangat kecil, demikian juga pendidik dengan status kepegawaian tetap.

Berdasarkan Tabel 11, kualitas 7 bentuk layanan pendidikan berdasarkan 3 jenis indikator

Tabel 7 Indikator Kesetaraan Layanan PAUD dan PNF Tahun 2012

\begin{tabular}{llrrrrrrr}
\hline No. & Jenis Program & PK & PAUD & TK & Paket A & Paket B & Paket C & Kursus \\
\hline 1 & PG PD/PG APK & -38.19 & -2.94 & -0.84 & 0.03 & 0.21 & 0.19 & -11.95 \\
2 & RG PD/IPG APK & 2.24 & 1.16 & 1.03 & 0.89 & 0.82 & 0.91 & 1.27 \\
3 & \%PDS-Swt & - & - & 95.88 & - & - & - & - \\
\hline
\end{tabular}

Tabel 8 Indikator Kepastian Layanan PAUD dan PNF Tahun 2012

\begin{tabular}{|c|c|c|c|c|c|c|c|c|}
\hline No. & Jenis Program & PK & PAUD & TK & Paket A & Paket B & Paket C & Kursus \\
\hline 1 & APK & - & 19.94 & 28.73 & 0.26 & 1.07 & 1.96 & - \\
\hline 2 & AMK & - & - & 20.08 & - & - & - & - \\
\hline
\end{tabular}

Tabel 9 Nilai Ketersediaan Layanan PAUD dan PNF Tahun 2012

\begin{tabular}{llrrrrrrrr}
\hline No. & \multicolumn{1}{c}{ Indikator } & PK & PAUD & TK & Paket A & Paket B & Paket C & Kursus & Rata2 \\
\hline 1 & Rasio PD/KB/Lbg & 100.00 & 85.05 & 89.60 & 88.12 & 85.85 & 91.51 & 68.19 & 86.90 \\
2 & Rasio P/KB/Lbg & 97.28 & 77.34 & 80.95 & 75.76 & 92.44 & 95.65 & 58.42 & 82.55 \\
3 & \%Lbg Pem & - & - & - & - & - & - & 58.17 & 58.17 \\
& Ketersediaan & 98.64 & 81.20 & 85.28 & 81.94 & 89.15 & 93.58 & 61.59 & 84.48 \\
\hline
\end{tabular}


sebesar 83,85 , artinya tercapai hampir $85 \%$. TK mendukung kesetaraan yang terbesar 96,03 dan terkecil pada PK sebesar 57,56. Kecilnya kesetaraan PK karena peserta didiknya sangat lebih banyak perempuan daripada laki-laki.

Berdasarkan Tabel 12, kepastian memperoleh layanan dari 7 bentuk layanan pendidikan berdasarkan 2 jenis indikator sebesar 73,45, artinya ketercapaian kepastian memperoleh layanan belum ada tiga perempat.
Hal ini akibat APK kepastian layanan program Paket B sangat kecil.

Berdasarkan Tabel 13, nilai ketersediaan, kualitas, kesetaraan dan kepastian digabungkan menjadi satu. Dari 7 bentuk layanan pendidikan dihasilkan kinerja layanan PAUD dan PNF sebesar 75,43 atau tercapai hanya tiga perempat. Kecilnya kinerja PAUD dan PNF disebabkan karena kinerja kursus yang terkecil sebesar 67,99 dan terbesar pada program Paket C

Tabel 10 Nilai Kualitas Layanan PAUD dan PNF Tahun 2012

\begin{tabular}{|c|c|c|c|c|c|c|c|c|c|}
\hline No. & Jenis Program & PK & PAUD & TK & Paket A & Paket B & Paket C & Kursus & Rata2 \\
\hline 1 & \%PD Usia & 37.35 & 90.05 & - & 10.55 & 14.31 & 30.35 & - & 36.52 \\
\hline 2 & $\% \mathrm{PU}$ & - & - & - & 89.68 & 91.13 & 93.90 & - & 91.57 \\
\hline 3 & \%Lls & - & - & - & 67.59 & 71.63 & 76.33 & 59.72 & 68.82 \\
\hline 4 & Rasio PD/P & 87.61 & 86.96 & 85.23 & 86.92 & 48.96 & 51.44 & 32.01 & 68.45 \\
\hline 5 & \%PS1+ & 42.55 & 11.48 & 21.74 & 41.88 & 57.13 & 73.70 & 54.92 & 43.34 \\
\hline 6 & \%PGuru & 50.08 & 50.38 & - & 59.40 & 68.88 & 72.74 & - & 60.30 \\
\hline 7 & $\% \mathrm{PPn}$ & 72.64 & 52.48 & 51.33 & 88.51 & 84.39 & 87.18 & 94.35 & 75.84 \\
\hline 8 & $\%$ PLn & 57.87 & 53.22 & - & - & - & - & - & 55.55 \\
\hline 9 & \%PT & - & - & 43.12 & - & - & - & - & 43.12 \\
\hline 10 & \%PAS1+ & 69.16 & 67.47 & 21.56 & 47.06 & 54.06 & 60.28 & - & 53.27 \\
\hline \multirow[t]{2}{*}{11} & $\% \mathrm{PAPn}$ & - & 56.82 & 52.46 & 77.88 & 75.09 & 74.90 & - & 67.43 \\
\hline & Kualitas Layanan & 59.61 & 58.61 & 45.91 & 63.28 & 62.84 & 68.98 & 60.25 & 59.92 \\
\hline
\end{tabular}

Tabel 11 Nilai Kesetaraan Layanan PAUD dan PNF Tahun 2012

\begin{tabular}{llrrrrrrrr}
\hline No. & Jenis Program & PK & PAUD & TK & Paket A & Paket B & Paket C & Kursus & Rata2 \\
\hline 1 & PG PD/PG APK & 64.73 & 97.23 & 97.82 & 99.87 & 99.75 & 97.88 & 86.82 & 92.01 \\
2 & RG PD/IPG APK & 50.40 & 87.20 & 93.16 & 76.95 & 82.03 & 61.58 & 77.44 & 75.54 \\
3 & \%PD-Swt & - & - & 97.10 & - & - & - & - & 97.10 \\
& Kesetaraan Layanan & 57.56 & 92.21 & 96.03 & 88.41 & 90.89 & 79.73 & 82.13 & 83.85 \\
\hline
\end{tabular}

Tabel 12 Nilai Kepastian Layanan PAUD dan PNF Tahun 2012

\begin{tabular}{lrrrrrrrr}
\hline No. Jenis Program & PK & PAUD & TK & Paket A & Paket B & Paket C & Kursus & Rata2 \\
\hline 1 APK & - & 67.49 & 82.72 & 81.55 & 58.98 & 83.48 & - & 74.85 \\
2 AMK & - & - & 68.80 & - & - & - & - & 68.80 \\
$\quad$ Kepastian Layanan & - & 67.49 & 75.76 & 81.55 & 58.98 & 83.48 & - & 73.45 \\
\hline
\end{tabular}


Tabel 13 Kinerja Layanan PAUD dan PNF Tahun 2012

\begin{tabular}{rlrrrrrrrr}
\hline No. & Misi Pendidikan & PK & PAUD & TK & Paket A & Paket B & Paket C & Kursus & Rata2 \\
\hline 1 & Ketersediaan & 98.64 & 81.20 & 85.28 & 81.94 & 89.15 & 93.58 & 61.59 & 84.48 \\
2 & Kualitas & 59.61 & 58.61 & 45.91 & 63.28 & 62.84 & 68.98 & 60.25 & 59.92 \\
3 & Kesetaraan & 57.56 & 92.21 & 96.03 & 88.41 & 90.89 & 79.73 & 82.13 & 83.85 \\
4 & Kepastian & - & 67.49 & 75.76 & 81.55 & 58.98 & 83.48 & - & 73.45 \\
& Kinerja & 71.94 & 74.88 & 75.74 & 78.79 & 75.46 & 81.44 & 67.99 & 75.43 \\
\hline
\end{tabular}

sebesar 81,44 . Untuk itu, perlu perbaikan penyelenggaraan kursus terutama pada ketersediaan dan kualitas layanan kursus. Bila dilihat dari misi pendidikan maka kualitas layanan pendidikan yang terkecil sebesar 59,92 dan terbesar pada ketersediaan layanan pendidikan sebesar 84,48. Untuk itu, perlu perbaikan pada kualitas TK, PK, dan PAUD agar kualitas meningkatkan, walaupun program lainnya juga perlu diperbaiki kualitasnya karena juga hanya sekitar 60.

\section{Simpulan dan Saran \\ Simpulan}

Berdasarkan hasil dan bahasan maka dapat disimpulkan tiga hal. Pertama, layanan PAUD dan PNF secara nasional sudah cukup baik. Hal ini tampak sebaran peserta didik sebesar 12,9 juta, 33,0 ribu kelompok belajar, 181,2 ribu lembaga, 575,6 ribu orang pendidik, dan 160,9 ribu orang pengelola. Dengan melihat potensi seperti itu maka dapat dikatakan bahwa PAUD dan PNF cukup signifikan membantu anak atau penduduk usia sekolah bersekolah, yang pada akhirnya membantu fungsi pendidikan formal dalam mencerdaskan kehidupan bangsa.

Kedua, indikator layanan PAUD dan PNF dilihat dari 4 misi pendidikan juga cukup menggembirakan. Ketersediaan layanan dihitung dari tiga indikator pendidikan. Kepadatan kelompok belajar/lembaga pada 7 bentuk layanan pendidikan cukup besar yaitu 60 orang, terkecil pada PK (10 orang) dan terbesar pada kursus (91 orang). Pendidik per kelompok belajar/ lembaga sebesar 3, terkecil pada PK (1 orang) dan terbesar pada Paket C (6 orang). Kursus yang dibiayai pemerintah pusat dan daerah sekitar 11,38\%. Kualitas dihitung dari 11 indikator yang terdiri dari tiga indikator terkait peserta didik, 6 indikator pendidik, dan 2 indikator pengelola. R-PD/P dari 7 program sebesar 22 orang, terkecil pada Paket C (6 orang) dan terbesar pada Kursus (39 orang). \%PS1+ sebesar 29,13\%, terkecil pada PAUD (14,49\%) dan terbesar pada Paket C $(77,01 \%)$. \%PPn sebesar $85,9 \%$, terkecil pada Paket B $(43,08 \%)$ dan terbesar pada TK $(7,42 \%)$. Kesetaraan dihitung dari 3 indikator, PG PD/PG APK terbaik adalah Paket $A(0,03 \%)$ dan terburuk adalah PK (-38,19\%), RG PD/IPG APK terbaik adalah TK $(1,03)$ mendekati setara dan terburuk adalah PK $(2,24)$. Kepastian dihitung dari 2 indikator. APK terbaik pada TK $(28,73 \%)$ dan terburuk adalah Paket A $(0,26 \%)$ dan AMK TK sebesar $20,08 \%$ berarti hanya seperlima penduduk yang masuk TK.

Ketiga, nilai kinerja layanan PAUD dan PNF dihitung menggunakan 4 misi pendidikan dengan 18 jenis indikator juga menunjukkan hal yang cukup positif. Hasilnya, bahwa kinerja ketersediaan layanan sebesar 84,48, kinerja kualitas layanan sebesar 59,92, kinerja kesetaraan layanan sebesar 83,85, dan kinerja kepastian layanan sebesar 73,45. Dengan menggabungkan 4 misi pendidikan maka PK sebesar 71,94, PAUD sebesar 74,88, TK sebesar 75,74, Paket A sebesar 78,79, Paket B sebesar 75,46, Paket $C$ sebesar 81,44, dan kursus sebesar 67,99 sehingga kinerja layanan PAUD dan PNF sebesar 75,43 atau tercapai tiga perempat dari 100. Dengan demikian, dari 7 bentuk layanan pendidikan maka kinerja terbaik ada pada program Paket $\mathrm{C}$ dan terburuk pada PK, dari misi pendidikan maka terbaik adalah ketersediaan layanan PAUD dan PNF, sedangkan terburuk adalah kualitas layanan PAUD dan PNF. 


\section{Saran}

Berdasarkan simpulan di atas maka diberikan tiga saran. Pertama, layanan PAUD dan PNF yang ditelaah dari 7 bentuk layanan pendidikan telah dapat menyerap peserta didik cukup banyak. Oleh karena itu, perlu dijaga dan dirawat agar tujuan PAUD dan PNF sebagai pengganti/ penambah/pelengkap pendidikan formal dapat terlaksana dengan lebih baik melalui evaluasi kegiatan dengan kelengkapan data.

Kedua, indikator untuk melihat kualitas pada semua program PAUD dan Nonformal tidak sama karena perbedaan data yang dimiliki. Oleh karena supaya diusahakan data yang sama untuk semua program PAUD dan PNF, misalnya pendidik yang mendapat pelatihan tentang PAUD dan PNF sehingga indikator kualitas menjadi lengkap. Selain itu, perlu ditingkatkan kualifikasi pendidik, asal pendidik, pelatihan pendidik, kualifikasi pengelola, dan pelatihan pengelola sehingga apa yang mereka kerjakan akan mendukung kualitas layanan PAUD dan PNF.
Ketiga, kinerja kualitas layanan PAUD dan PNF menunjukkan nilai yang paling rendah sebesar 59,92, oleh karena itu perlu ditingkatkan. Kualitas yang rendah terjadi pada peserta didik usia sekolah, karena ternyata kebijakan yang ada tidak dilaksanakan dengan baik di lapangan, misalnya program Paket A seharusnya untuk anak usia 7-12 tahun ternyata hanya $11 \%$ dan usia lainnya $89 \%$ bersekolah pada program Paket A, program Paket B seharusnya untuk anak usia 13-15 tahun ternyata hanya $18 \%$ dan usia lainnya $82 \%$ bersekolah pada program Paket B, program Paket $\mathrm{C}$ seharusnya untuk anak usia 16-18 tahun ternyata hanya 30\% dan usia lainnya $70 \%$ bersekolah pada program Paket $\mathrm{C}$. Kualitas yang rendah juga terjadi karena pendidik dan pengelola yang berijazah S1 dan lebih tinggi juga sangat rendah, pendidik yang berstatus tetap juga rendah. Bila ketiga jenis indikator tersebut dapat ditingkatkan maka diharapkan nilai kualitas layanan PAUD dan PNF akan meningkat. Pada akhirnya, kinerja PAUD dan PNF akan meningkat.

\section{Pustaka Acuan}

Arikunto, S. 2010. Prosedur Penelitian Suatu Pendekatan Praktek, Jakarta: Rineka Cipta.

Departemen Pendidikan Nasional. 2007. Peraturan Menteri Pendidikan Nasional Nomor 49 Tahun 2007 tentang Standar Pengelolaan Pendidikan Nonformal, Jakarta.

Dilihatya.com. Agustus 2014). Pengertian Indikator Menurut para Ahli. http://dilihatya.com/ 1133/Pengertian-Indikator-Menurut-para-Ahli, diakses 22 September 2014.

Faridy, F. 8 Desember 2014. Peran Guru Laki-laki terhadap PAUD. www.kompasiana.com/faieza/ peran-guru-laki-laki-terhadap-paud-54f924cda33311fc078b474f, diakses 13 Pebruari 2014.

Sulton, M. 2012. Pengertian Indikator dalam Pendidikan. http://studentgoblog.blogspot.com/ 2012/04/pengertian-indicator.html. diakses 20 September 2014.

http://www.kinerja.or.id/. diakses 22 September 2014r

Kementerian Pendidikan Nasional. 2010. Rencana Strategis Kementerian Pendidikan Nasional 2010-2014. Jakarta.

Kintamani, I. 2012. Kinerja Pendidikan Kesetaraan sebagai Salah Satu Jenis Pendidikan Nonformal. Jurnal Pendidikan dan Kebudayaan, 18(1). hlm. 65-84.

Kintamani, I. 2013. Indikator Misi Pendidikan 5K Berdasarkan Rencana Strategis Pendidikan 20102014. Jakarta: Pusat Data dan Statistik Pendidikan. 
Mangkunegara, A. P. 2000. Manajemen Sumber Daya Manusia Perusahaan. Bandung: PT Remaja Rosdakarya.

Pusat Data dan Statistik Pendidikan. 2013a. Statistik PAUD Tahun 2012/2013. Jakarta: Kementerian Pendidikan dan Kebudayaan.

Pusat Data dan Statistik Pendidikan. 2013b. Statistik Pendidikan Nonformal Tahun 2012/2013. Jakarta: Kementerian Pendidikan dan Kebudayaan.

Sekretariat Negara. 2003. Undang-Undang RI Nomor 20 Tahun 2003 tentang Sistem Pendidikan Nasional. Jakarta.

Sekretariat Negara. 2010. Peraturan Pemerintah RI Nomor 17 Tahun 2010 tentang Pengelolaan dan Penyelenggaraan Pendidikan. Jakarta.

Soehartono, I. 2002. Metode Penelitian Sosial. Bandung: PT Remaja Rosdakarya.

Sudjana, D. 2001. Pendidikan Nonformal: Filsafat, Asas, dan Teori Pendukung Asas. Bandung: Falah Production.

Sulistyarini, A.T. 2003. Manajemen Sumber Daya Manusia. Jakarta: Graha Ilmu. 